\title{
Advances in managing type 2 diabetes: challenging old paradigms and developing new ones
}

\author{
Naveed Sattar
}

Address: Institute of Cardiovascular \& Medical Sciences, BHF Glasgow Cardiovascular Research Centre, University of Glasgow, 126 University Avenue, Glasgow, G12 8TA, UK

Email: naveed.sattar@glasgow.ac.uk

Fl000Prime Reports 2014, 6:42 (doi:10.12703/P6-42)

All FI000Prime Reports articles are distributed under the terms of the Creative Commons Attribution-Non Commercial License (http://creativecommons.org/licenses/by-nc/3.0/legalcode), which permits non-commercial use, distribution, and reproduction in any medium, provided the original work is properly cited.

The electronic version of this article is the complete one and can be found at: http://fl000.com/prime/reports/m/6/42

\begin{abstract}
As is well known, diabetes rates continue to escalate worldwide, adding cost and disease burden to all health-care institutions. Over the last few years, however, a number of diabetes paradigms have been challenged, not least on the best methods to lessen or delay the development of co-morbidities, in particular cardiovascular disease (CVD) (i.e. targeting blood pressure, cholesterol, and smoking will do more than intensive glucose control). In addition, recent research has offered some hope to potentially reverse diabetes in motivated individuals, with resultant larger and longer trials of such interventions about to commence. This brief review summarizes these important recent developments and suggests that, while many new drugs are being added to the diabetes therapeutic armory, more could and should be done to target sustainable weight change in our patients for multiple health benefits.
\end{abstract}

\section{Glycemia paradigm: moving from intensive glycemia lowering in all to individually tailored glycemic goals}

The summary results [1] of the four recent trials examining benefits of intensified glucose control have surely given us an unmistakable clinical steer. We know now that benefits of such policy are minor in terms of vascular benefit, especially when compared with the much larger benefits stemming from lipid-lowering and anti-hypertensive therapy [2]. In addition, aiming for very low glycemia target in some subgroups - including those with longer duration of diabetes or evidence of existing microvascular or macrovascular complications - may even be associated with an increase in mortality risk. Some guideline committees - e.g. the Scottish Intercollegiate Guidelines Network (SIGN) - have responded by calling for less strict targets for glycated hemoglobin (HbA1c). SIGN recommends that "an HbA1c target of $7.0 \%(53 \mathrm{mmol} / \mathrm{mol})$ among people with type 2 diabetes is reasonable to reduce risk of microvascular disease and macrovascular disease. A target of $6.5 \%$ ( $48 \mathrm{mmol} / \mathrm{mol})$ may be appropriate at diagnosis" [3]. These latter suggestions would seem entirely sensible given the current evidence base. They also link well with recent suggestions for a patientcentered approach towards the management of hyperglycemia in type 2 diabetes, with patient characteristics such as motivation levels, age/life-expectancy, duration of disease, co-morbidity burden, and hypoglycemia risks, requiring consideration in determining goals and therapy approaches [4].

Other related trials reinforce the notion that management of diabetes patients is much more than just targeting glycemia

If we look at three recently published cardiovascular endpoint trials in diabetes patients, but with differing interventions (Table 1), the foregoing observations are strongly reiterated. We turn first to the Look AHEAD (Action for Health in Diabetes) study [5], a study of lifestyle intervention in diabetes. Here, the patients in the intensive lifestyle arm lost considerable weight in the first year $(8.6 \%)$ but inevitably this advantage over the control 
Table I. Summary of cardiovascular disease end-point trials in diabetes trials

\begin{tabular}{|c|c|c|c|c|c|c|}
\hline Trial & $\begin{array}{l}\text { Nature of } \\
\text { intervention }\end{array}$ & Baseline HbA Ic & $\begin{array}{l}\text { Intervention } \\
\text { effect on glycemia }\end{array}$ & Duration of trial & $\begin{array}{l}\text { Primary CVD } \\
\text { outcome }\end{array}$ & Comment \\
\hline Look AHEAD [4] & $\begin{array}{l}\text { Intensive lifestyle } \\
\text { versus usual care }\end{array}$ & $7.3 \%$ & $\begin{array}{l}\sim 0.27 \% \text { over first } \\
4 \text { years }\end{array}$ & 9.6 years & Null & $\begin{array}{l}\text { Other CVD risks } \\
\text { very low at onset } \\
\text { and modest HbAlc } \\
\text { difference }\end{array}$ \\
\hline ORIGIN [5] & Basal insulin & $6.4 \%$ & $\sim 0.3 \%$ & 6.2 years & Null & $\begin{array}{l}\text { Flat part of } \mathrm{HbAlc} \\
\text { to CVD curve }\end{array}$ \\
\hline SAVOR [6] & $\begin{array}{l}\text { DPP-4 inhibitor, } \\
\text { saxagliptin }\end{array}$ & $8.0 \%$ & $\sim 0.3 \%$ & 2.1 years & Null & $\begin{array}{l}\text { Short duration and } \\
\text { minimal HbAlc } \\
\text { difference }\end{array}$ \\
\hline
\end{tabular}

Abbreviations: CVD, cardiovascular disease; HbA I c, glycated hemoglobin; Look AHEAD, Look Action for Health in Diabetes; ORIGIN, Outcome Reduction With Initial Glargine Intervention; SAVOR, Saxagliptin Assessment of Vascular Outcomes Recorded in patients with diabetes mellitus.

group lessened over time so that by 4 years, the average weight difference was only around $5 \%$ and the average glycemia difference only $0.27 \%$. Of course, this trial ended prematurely at 9.6 years because of futility, with no difference in event rates between intensive lifestyle and control arms. Although this finding surprised many, a close inspection of the baseline characteristics of the trial participants recruited into Look AHEAD reveals very low cardiovascular risk factors despite body mass indices of around 36 units. Indeed, only around 4\% smoked, mean blood pressure was around 129/70 mm Hg, and lowdensity lipoprotein (LDL) cholesterol was around $2.90 \mathrm{mmol} / \mathrm{l}$. The weight loss intervention, of course, improved glycemia (but only very modestly so), effected blood pressure minimally, and had no effect on LDL cholesterol. In other words, the key causal CVD risk factors in Look AHEAD were very well addressed to begin with and did not (or could not) improve appreciably further with lifestyle intervention.

Turning next to the ORIGIN (Outcome Reduction With Initial Glargine Intervention) study [6], a very wellconducted study that tested the hypothesis that early basal insulin treatment in diabetes to target glycemia towards normal levels may provide CVD benefit, we find once again a null result despite 6.2 years of follow-up. Here, two recently established glycemia facts about the trial would have led current researchers to doubt the likelihood of its showing a positive result; hindsight is, of course, a wonderful thing. Firstly, baseline HbA1c in ORIGIN participants was around only 6.4\%, a level well below the threshold of around 7\%, above which CVD risk appeared to manifest in the ADVANCE (Action in Diabetes and Vascular Disease) trial. In other words, the glycemia levels were at the flat part of the curve with respect to CVD. Secondly, the difference in HbA1c afforded by the basal insulin was only around $0.3 \%$, and as noted above, such differences in glycemic control are unlikely to afford detectable CVD risk protection over even modest periods of time, irrespective of the starting HbA1c level. Of course, there was always a potential that insulin had a net beneficial pleiotropic effect independent of its glycemia action to lessen CVD, but, in the end, this proved not to be the case.

The final trial of note was one of the recent DPP-4 trials, SAVOR (Saxagliptin Assessment of Vascular Outcomes Recorded in patients with diabetes mellitus) [7], which showed no improvement in CVD events with saxagliptin. While the mean HbA1c at baseline ( $8.0 \%)$ was at a level where it could be appreciably reduced, the very modest difference in HbA1c ( $0.3 \%)$ between the intervention and placebo control arms could simply not lower CVD risk over such a short duration of time. Of course, the investigators and research community were somewhat misled by the results of meta-analysis of smaller-scale studies [8], which hinted at sizeable CVD benefits of DPP-4s; it therefore appears that only larger-scale trials with proper adjudication of incident CVD events may allow us to get to the truth of the matter. Larger trials also reveal potential harms not able to be picked up in small-scale, short, glycemia-targeted trials. Indeed, the unexpected finding of increase in heart failure hospitalizations with saxagliptin [7] requires further investigation and could yet be a class effect.

Overall, the above trials and observations more strongly than ever tell us that to lessen CVD risk in diabetes requires good control of cholesterol and blood pressure and a reduction in smoking levels, whereas CVD effects of glycemia reduction are more modest. Of course, diabetes care is multifaceted and good glycemia control is more strongly associated with the prevention of microvascular complications. Equally, while weight loss may not 
necessarily lower CVD risk in the short to medium term in obese, but otherwise well-controlled, patients with diabetes, we need to be aware that nearly all patients would benefit from and would welcome intentional weight loss. Indeed, recent evidence strongly reiterates the importance of weight loss to quality of life in diabetes [9], yet few of us discuss or have the time or expertise to discuss weight change with our patients. Interestingly, in this respect, a recent trial suggested that the National Health Service (NHS) is, in fact, only around half as good as commercial weight loss organizations in helping our patients lose weight [10].

\section{Diabetes reversal or remission: a realistic prospect?}

If we extend the discussion on big weight change, work in recent years has improved our knowledge of the mechanisms linking weight gain to development of type 2 diabetes. In susceptible individuals, the gain of ectopic fat within the liver and muscle, as well as potentially other tissues, promotes insulin resistance and thereby accelerates development of hyperglycemia [11]. Ectopic fat may also be partially responsible for pancreatic insufficiency, although more work is needed to confirm this latter possibility, but here the concept of inevitable beta cell death is now being questioned from several angles [12]. Consequently, it should be no surprise to see reversal of diabetes upon major calorie restriction in the short term with use of low-energy liquid diets, when parallel reductions in ectopic fat are evident, particularly in the liver [13]. These insights have provided a much-needed boost to better target weight change to prevent or delay diabetes and have also helped promote a research agenda to test diabetes reversal (and, critically, determine its sustainability) in the NHS clinical setting. This latter potential is being tested in clinical trials.

\section{Back to the future: many new drugs but time to get serious about weight change}

The above observations are important as we think about the care of an increasing population of patients with diabetes. We know now that, to lower CVD, robust management of the usual risk factors (cholesterol, blood pressure, and smoking) are critically important, perhaps more so than lowering glucose levels, though the latter remains important to lessen microvascular complications. In targeting glucose, the diabetes therapeutic armory has increased with new ways to lessen glycemia, some working on the incretin pathway (DPP-4s/GLP-1 agonists) [14] and some working to lower renal glucose thresholds and remove excess glucose via urination (SGLT2 class) [15]. However, all these new therapies are costly, and all must be tested in ever-larger clinical trials to measure their true safety (effects cannot be fully predicted on the basis of mechanisms of actions) and benefits. However, with more regular glucose and HbA1c testing, diabetes is being diagnosed on average much sooner after its onset than one or two decades ago and at a time when patients may be more able to make sustainable lifestyle changes. At the same time, individuals at high risk of diabetes, suitable for intensive lifestyle to prevent conversion, are also more easily identified by using simple diabetes risk scores initially and then, as required, fasting glucose or HbA1c [16]. These changes, allied to new knowledge linking weight to both diabetes pathogenesis and patients' quality of life, should reinvigorate the diabetes fraternity to improve their management of weight change. To do so, we should adopt and implement, wherever possible, the best pragmatic and cost-effective evidence to help our patients lose weight or alter their weight trajectory. If this can be achieved, the potential gains could be substantial, and it may also be possible that some highly motivated patients could even reverse their diabetes, if only for a short period of time. These are achievable goals and should be given greater consideration in the future.

\section{Abbreviations}

CVD, cardiovascular disease; HbA1c, glycated hemoglobin; LDL, low-density lipoprotein; Look AHEAD, Look Action for Health in Diabetes; NHS, National Health Service; ORIGIN, Outcome Reduction With Initial Glargine Intervention; SIGN, Scottish Intercollegiate Guidelines Network.

\section{Disclosures}

Naveed Sattar has consulted for AstraZeneca (London, UK), Bristol-Myers Squibb Company (Princeton, NJ, USA), Amgen (Thousand Oaks, CA, USA), Sanofi (Paris, France), and Boehringer Ingelheim (Ingelheim am Rhein, Rhineland-Palatinate, Germany).

\section{References}

I. Control Group, Turnbull FM, Abraira C, Anderson RJ, Byington RP, Chalmers JP, Duckworth WC, Evans GW, Gerstein HC, Holman RR, Moritz TE, Neal BC, Ninomiya T, Patel AA, Paul SK, Travert F, Woodward $M$ : Intensive glucose control and macrovascular outcomes in type 2 diabetes. Diabetologia 2009, 52:2288-98.

FlOOOPrime RECOMMENDED

2. Ray KK, Seshasai SR, Wijesuriya S, Sivakumaran R, Nethercott S, Preiss D, Erqou S, Sattar N: Effect of intensive control of glucose on cardiovascular outcomes and death in patients with diabetes mellitus: a meta-analysis of randomised controlled trials. Lancet 2009, 373:1765-72.

3. SIGN clinical guideline: Management of diabetes. 2010 Scottish Intercollegiate Guidelines Network [http://www.sign.ac.uk/pdf/ sign I 16.pdf]

4. Inzucchi SE, Bergenstal RM, Buse JB, Diamant M, Ferrannini E, Nauck M, Peters AL, Tsapas A, Wender R, Matthews DR; American Diabetes Association (ADA); European Association for the Study of Diabetes 
(EASD): Management of hyperglycemia in type 2 diabetes: a patient-centered approach: position statement of the American Diabetes Association (ADA) and the European Association for the Study of Diabetes (EASD). Diabetes Care 2012, 35:1364-79.

\section{FlOOOPrime RECOMMENDED}

5. Look AHEAD Research Group, Wing RR, Bolin P, Brancati FL, Bray GA, Clark JM, Coday M, Crow RS, Curtis JM, Egan CM, Espeland MA, Evans M, Foreyt JP, Ghazarian S, Gregg EW, Harrison B, Hazuda HP, Hill JO, Horton ES, Hubbard VS, Jakicic JM, Jeffery RW, Johnson KC, Kahn SE, Kitabchi AE, Knowler WC, Lewis CE, Maschak-Carey BJ, Montez MG et al.: Cardiovascular effects of intensive lifestyle intervention in type 2 diabetes. N Engl J Med 2013, 369:145-54.

\section{FlOOOPrime} RECOMMENDED

6. ORIGIN Trial Investigators, Gerstein HC, Bosch J, Dagenais GR, Díaz R, Jung H, Maggioni AP, Pogue J, Probstfield J, Ramachandran A, Riddle MC, Rydén LE, Yusuf S: Basal insulin and cardiovascular and other outcomes in dysglycemia. N Engl J Med 2012, 367:319-28.

\section{FloOOPrime} RECOMMENDED

7. Scirica BM, Bhatt DL, Braunwald E, Steg PG, Davidson J, Hirshberg B, Ohman P, Frederich R, Wiviott SD, Hoffman EB, Cavender MA, Udell JA, Desai NR, Mosenzon O, McGuire DK, Ray KK, Leiter LA, Raz I; SAVOR-TIMI 53 Steering Committee and Investigators: Saxagliptin and cardiovascular outcomes in patients with type 2 diabetes mellitus. N Engl J Med 2013, 369:1317-26.

\section{FlOOOPrime}

8. Patil HR, Al Badarin FJ, Al Shami HA, Bhatti SK, Lavie CJ, Bell DS, O'Keefe JH: Meta-analysis of effect of dipeptidyl peptidase-4 inhibitors on cardiovascular risk in type 2 diabetes mellitus. Am J Cardiol 2012, I l 0:826-33.

9. Grandy S, Fox KM, Bazata DD; SHIELD Study Group: Healthrelated quality of life association with weight change in type
2 diabetes mellitus: perception vs. reality. Int / Clin Pract 2013, 67:455-61.

\section{FlOOOPrime}

10. Jebb SA, Ahern AL, Olson AD, Aston LM, Holzapfel C, Stoll J, AmannGassner U, Simpson AE, Fuller NR, Pearson S, Lau NS, Mander AP, Hauner H, Caterson ID: Primary care referral to a commercial provider for weight loss treatment versus standard care: a randomised controlled trial. Lancet 20II, 378:I485-92.

\section{FlOOOPrime}

1I. Taylor R: Banting Memorial lecture 2012: reversing the twin cycles of type 2 diabetes. Diabet Med 2013, 30:267-75.

12. Bradley D, Conte C, Mittendorfer B, Eagon JC, Varela JE, Fabbrini E, Gastaldelli A, Chambers KT, Su X, Okunade A, Patterson BW, Klein S: Gastric bypass and banding equally improve insulin sensitivity and $\beta$ cell function. J Clin Invest 2012, 122:4667-74.

\section{FlOOOPrime} RECOMMENDED

13. Lim EL, Hollingsworth KG, Aribisala BS, Chen MJ, Mathers JC, Taylor R: Reversal of type 2 diabetes: normalisation of beta cell function in association with decreased pancreas and liver triacylglycerol. Diabetologia 20II, 54:2506-I4.

\section{FIOOOPrime}

14. Samson SL, Garber A: GLP-IR agonist therapy for diabetes: benefits and potential risks. Curr Opin Endocrinol Diabetes Obes 20I3, 20:87-97.

15. Boyle LD, Wilding JP: Emerging sodium/glucose co-transporter 2 inhibitors for type 2 diabetes. Expert Opin Emerg Drugs 2013, |8:375-9|.

16. Chatterton H, Younger T, Fischer A, Khunti K; Programme Development Group: Risk identification and interventions to prevent type 2 diabetes in adults at high risk: summary of NICE guidance. BMJ 20I2, 345:e4624.

\section{FlOOOPrime}

RECOMMENDED 